\title{
A Lagrangian analysis of water vapor sources and pathways for precipitations in East China in different stages of the East Asian summer monsoon
}

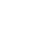

Laboratoire de Météorologie Dynamique, CNRS, Sorbonne Université, Ecole Normale Supérieure, Ecole Polytechnique, Paris, France

Atmospheric Science Program, Department of Geography, The Ohio State University, Columbus, Ohio, USA

Key Laboratory of Meteorological Disaster of Ministry of Education, Collaborative Innovation Center on Forecast and Evaluation of Meteorological Disasters, Nanjing University of Information Science \& Technology, Nanjing, 210044, China

\section{ZHENGYU LIU}

\section{LAURENT LI}

${ }^{*}$ Corresponding author address: Zhi-Hong Jiang, Key Laboratory of Meteorological Disaster of Ministry of Education, Collaborative Innovation Center on Forecast and Evaluation of Meteorological Disasters, Nanjing University of Information Science and Technology, 219 Ningliu Rd., Nanjing 210044, China.

Email: zhjiang@nuist.edu.cn 


\section{Abstract}

The Hybrid Single-Particle Lagrangian Integrated Trajectory (HYSPLIT) platform is used to simulate Lagrangian trajectories of air parcels in East China during the summer monsoon. The investigation includes four distinct stages of the East Asian Summer Monsoon (EASM) during its seasonal migration from south to north. Correspondingly, the main water vapor channel migrates from the West Pacific Ocean (PO) for the pre-monsoon in South China (SC) to the Indian Ocean (IO) for the monsoon in SC and in the Yangtze-Huaihe River Basin, and finally back to PO for the terminal stage of monsoon in North China. Further calculations permit to determine water vapor source regions and water vapor contribution to precipitations in East China. To a large extent, moisture leading to precipitation doesn't come from the strongest water vapor pathways. For example, the proportions of trajectories from IO are larger than $25 \%$ all the time, but moisture contributions to actual precipitations are smaller than $10 \%$. This can be explained by the large amount of water vapor lost in the pathways across moisture-losing areas such as the Indian Peninsula and Indochina Peninsula. Local water vapor recycling inside East China (EC) contributes significantly to regional precipitations, with contributions mostly over $30 \%$, although the trajectory proportions from sub-regions in EC are all under 10\%. This contribution rate can even exceed $55 \%$ for the terminal stage of monsoon in North China. Such a result provides an important guidance to understand the role of land surface conditions in modulating rainfall in North China.

Key words: Lagrangian trajectory, East Asian Summer Monsoon, Moisture transport pathways, Moisture source 


\section{Introduction}

Unlike tropical summer monsoons, such as the Indian monsoon or the West African monsoon, the East Asian summer monsoon (EASM) is characterized by the presence of a front between warm air masses from the south and cold air masses from the north (Wang, 2006; Chang, 2004). A rain belt is formed along the front. During the seasonal course in summer, the rain belt marks a clear migration from south to north, making different rainy periods in different regions in East China. It is well recognized that three major periods of rainfall take place in South China, the Yangtze River basin and North China (Zhou and Yu, 2005; Ding et al., 2008; Shi et al., 2009; Sun et al., 2011; Zhu et al., 2011; Sun and Wang, 2015). The rain belt, whatever its geographic position during its migration course from south to north, is always strongly related to moisture transport which is a necessary condition leading to precipitation (Huang et al. 1998; Jiang et al., 2006; Sun et al., 2011). It is of great significance to quantitatively determine the moisture source of the monsoon rainfall for its different phases.

Early researches mainly used the Eulerian approach to analyze moisture transport pathways. For the rainy period in South China, Lin et al. (2014) showed that southwesterly water vapor transports carrying moisture from the Bay of Bengal, West Pacific and from the southwest side of the Tibetan Plateau are major pathways. For the Meiyu rainy season in the Yangtze River Valley, Jiang et al. (2009) showed that water vapor is mainly from the southern Indian Ocean, the East African coast and the Arabian Sea. For rainfalls in North China, Xie and Ren (2008) indicated that water vapor mainly comes from the Bay of Bengal, South China Sea/west Pacific Ocean and the mid latitude westerlies. These researches mainly focus 
on the moisture transport channels during EASM, and indicated the significant changes for different stages of the summer monsoon.

However, the simple analysis of moisture transport with an Eulerian vision is unable to assess moisture origins from remote regions. It generally ignores any moisture changes during the transport, although some Eulerian variants with an online implementation of moisture tagging technique in global or regional climate models were proved to be very useful to understand water vapor sources (see Insua-Costa et al. 2018 and the relevant references there). When such a water vapor tracer scheme was incorporated into the regional model WRF, Dominguez et al. (2016) and Eiras-Barca et al. (2017) were able to investigate the origin of moisture for the North American monsoon and for two events of atmospheric river landfall causing catastrophic precipitations.

The most advanced methods that are widely used in recent years to determine moisture origin are based on Lagrangian models (Stohl and James, 2004, 2005; Dominguez et al. 2006; Dirmeyer et al. 2009), capable of calculating backward or forward trajectories of air parcels residing over the target region. They can trace pathways of the moisture transport and changes of physical quantities along the pathways. The Lagrangian methodology has been highly valued in investigating global moisture transport and regional moisture recycling. We can cite a few works to show the diversity of research topics that used the Lagrangian approach. Firstly, at global scale, Gimeno et al. (2010) presented results on the moisture contribution for each continent from the global ocean in different seasons. At regional scale, Brubaker et al. (2001) and Diem and Brown (2006) calculated the moisture sources for precipitations in the Mississippi River Basin and in South West America. Bertò et al. (2004), Perry et al. (2007), 
Sodemann and Stohl (2009), Bottyán et al. (2014) demonstrated that water vapor for rainfalls in South Europe come, for a large proportion, from the Mediterranean Sea.

In East China, there are also numerous studies using Lagrangian models. Drumond et al (2011a) revealed the main moisture source in different regions in China. Sun and Wang (2014, 2015) detected the origins of moisture over East China and semiarid grassland. However, different researches are still quite divergent. Chen et al. (2013) showed that moisture of summer rainfall in the Yangtze-Huaihe River Basin is mainly from the South China Sea and the Bay of Bengal. Drumond et al. (2011a) indicated that the moisture of East China is mainly from the East China Sea, the moisture of South China is mainly from the Bay of Bengal and the Arabian Sea. In recent works, Sun and Wang (2015) affirmed that the water vapor for precipitations in the Yangtze-Huaihe River Basin and in North China is mainly from local evaporation and from the West Pacific Ocean.

The divergence of results in the scientific literature has two major sources. First, the target area in East China is different among different publications. There has been a lack of systematic investigation for different regions and for the whole seasonal course when the East Asian summer monsoon migrates from south to north. Second, since the calculations of Lagrangian trajectories require heavy computation, many existing studies have been limited to short periods, which may impact the stability and robustness of their results. It is thus desirable to study different phases during the seasonal migration course of the rainfalls in East China for a long time period.

In this article, based on the HYSPLIT platform of Lagrangian trajectories, we systematically analyze the variation of water vapor transport in East China during different 
110

111

112

phases of EASM. Our analysis covers the period from 1961 to 2010. Advanced diagnostics are performed to assess moisture transport pathways, moisture sources and contributions to precipitation in each phase of EASM.

The article is organized as follows: the data and analyzing methods are described in Section 2. Section 3 presents main results on the water vapor sources and contributions from different regions during the northward propagation of EASM. It furthermore quantifies the proportion of trajectories and the contribution of water vapor to precipitations during the seasonal course of EASM. Conclusions are drawn in the last Section.

\section{Data and methods}

\subsection{Data}

We used the reanalysis data taken from NOAA-National Centers for Environmental Prediction (NCEP)/National Center for Atmospheric Research (NCAR). Global pressure-level data were reprocessed into the HYSPLIT compatible format in the Air Resources Laboratory (ARL), NOAA, U.S. They are available since 1948 at 6 hourly temporal resolution and $2.5^{\circ}$ (latitude/longitude grid) spatial resolution with 17 levels in the vertical. Data have been downloaded from the ARL's archives (http://ready.arl.noaa.gov/gbl_reanalysis.php).

\subsection{Determination of the rainy season course in East China}

The rainy season course in East China is directly taken from the National Climate Bulletin published annually by the National Climate Center and the Central meteorological observatory (http://cmdp.ncc-cma.net/cn/monitoring.htm\#). As commonly practiced (Jiang et al., 2006, Sun and Wang, 2014, 2015, Zhou and Yu, 2005 and Ding et al., 2008), the rainy season course in East China is divided into three periods, and characterized by abundant 
rainfalls in three geographical regions which are, from south to north, South China (SC), the Yangtze-Huaihe River (YHR) basin and North China (NC). Data period covers from 1961 to 2010. The three areas are shown in Figure 1 with the following coordinates: $20^{\circ} \mathrm{N}-26^{\circ} \mathrm{N}$, $106^{\circ} \mathrm{E}-120^{\circ} \mathrm{E} ; 28^{\circ} \mathrm{N}-34^{\circ} \mathrm{N}, 110^{\circ} \mathrm{E}-123^{\circ} \mathrm{E} ; 35^{\circ} \mathrm{N}-43^{\circ} \mathrm{N}, 110^{\circ} \mathrm{E}-120^{\circ} \mathrm{E}$.

The situation in SC can be divided into two distinct sub-periods separated by the onset of the South China Sea (SCS) summer monsoon which induces different characteristics of atmospheric circulation in South China and associated water vapor transport (Shen et al., 1982; Chen and Zhu et al., 1991; Lin et al., 2014). Before the onset of SCS summer monsoon, the water vapor transport in South China is associated with westerly wind belt and South China Sea sea-level pressure high. With the onset and strengthening of the SCS monsoon, the cross-equatorial flow from the Southern Hemisphere intensifies and connects with the water vapor channel from the Bay of Bengal. Regarding the onset date of SCS monsoon, we use that defined by Wang et al. (2004), that is, the day when the $850 \mathrm{hPa}$ zonal winds averaged over the central $\operatorname{SCS}\left(5^{\circ}-15^{\circ} \mathrm{N}, 110^{\circ}-120^{\circ} \mathrm{E}\right)$ shift from westerlies to easterlies. Figure 2 shows the beginning and ending dates of the four periods characterizing the rainy season course of East China from 1961 to 2010. The average start days of the four periods are Apr 6, May 17, Jun 8 and July 16. The average end days are May 16, Jun 1, July 17 and Aug 18. As shown in Fig. 2, there is a large interannual variability for the timing and duration of these four sub-periods, which obligates us to use precise beginning and end dates in our statistics of trajectories.

\subsection{Methods}

2.3.1 HYSPLIT water vapor tracking simulation The National Oceanic and Atmospheric Administration (NOAA) Hybrid Single-Particle 
154

155

156

157

158

159

160

161

162

163

164

Lagrangian Integrated Trajectory (HYSPLIT) model (Draxler and Hess, 1998; Draxler and Rolph, 2011) is used in this paper for trajectories and tracks of air parcels. The back-trajectory algorithm is applied to all stations inside the three target areas. From their initial position, back-trajectories are calculated to cover all times between the beginning and the end of each of the four sub-periods of the monsoon propagation course. We use six levels at 100, 500, 1500, 3000, 5000 and $9000 \mathrm{~m}$ as our initial height of particles release. They roughly correspond to the near surface layer, levels at 925, 850, 700, 500 and $300 \mathrm{hPa}$ respectively. All parcels were integrated backward in time, until 10 days. Outputs were recorded every 6 hours with variables indicating the position (latitude, longitude, and altitude) and meteorological conditions (temperature, specific humidity, and geopotential height) for further analysis and diagnostics (Jiang et al. 2017). In particular, we averaged all trajectories in each of the five main moisture source areas, which helps us to get actual moisture transport pathways.

2.3.2 Evaporation-minus-Precipitation diagnosis method (E-P) to deduce source/sink regions of water vapor

Water vapor in an air parcel changes when evaporation or precipitation takes place, increasing with the former and decreasing with the latter. It is thus clear that a correct determination of the source and sink characteristics of the water vapor transport has to take into account processes of evaporation and precipitation following the trajectory. Stohl and James (2004, 2005) proposed such a diagnostic method, commonly called Evaporation-minus-Precipitation method to consider the change of moisture content with time as the air parcel travels. The budget equation can be written as follows: 


$$
e-p=m \frac{d q}{d t}
$$

177

178

where e and $\mathrm{p}$ are the rates of evaporation and precipitation, respectively, $\mathrm{q}$ is the specific humidity and $\mathrm{m}$ is the mass of the air parcel. For a given air parcel, when $\mathrm{q}$ decreases, precipitation is larger than evaporation, and the parcel loses water vapor. When q increases, evaporation is larger than precipitation, and the parcel gains water vapor. Summing the $\mathrm{e}-\mathrm{p}$ of all air parcels residing in the atmospheric column over an area A, the surface net water flux in the area can be given by the following equation:

$$
\mathrm{E}-\mathrm{P} \approx \frac{\sum_{k=1}^{K}(\mathrm{e}-\mathrm{p})}{A}
$$

where $\mathrm{E}$ and $\mathrm{P}$ are the total evaporation and precipitation in the column and $\mathrm{K}$ is the number of particles over the area. Equation (2) can be regarded as a Lagrangian transformation of the Eulerian atmospheric moisture budget equation:

$$
\mathrm{E}-\mathrm{P}=\frac{\partial W}{\partial t}+\nabla \cdot \frac{1}{g} \int_{0}^{P_{s}} q \vec{v} d \mathrm{p}
$$

where $\mathrm{W}=\frac{1}{g} \int_{0}^{P_{s}} q d \mathrm{p}$ is the vertically-integrated water vapor or precipitable water in the column, $\mathrm{g}$ is the gravitational acceleration, $\vec{v}$ is wind. $\mathrm{p}$ is atmospheric pressure and Ps is pressure at surface. The last term in Eq. 3 represents the divergence of vertically-integrated water vapor flux. Stohl and James $(2004,2005)$ showed that when using a large enough number of particles, the Lagrangian and Eularian methods give almost identical results. So, the E-P results can be obtained, and the overall water vapor budget in a certain region can be further determined. The case E-P $>0$ indicates that the area is source of water vapor to the precipitation in target region, whereas when E-P $<0$ the area is sink to the precipitation to the target region. More details of this Evaporation-minus-Precipitation method can be found in Stohl and James (2004, 2005) and Sodemann and Zubler (2010). 
2.3.3 The improved areal source-receptor attribution method

The Evaporation-minus-Precipitation diagnosis can be used to determine the regional source and sink characteristics of the water vapor, but it cannot quantify the composition of actual contribution of various water vapor sources to the precipitation in the considered area. For example, a region of high positive Evaporation-minus-Precipitation value can almost certainly be considered as a moisture source region. However, the air parcels passing over this region to a target region may not carry a large amount of moisture from this source region into the target region. This issue of water vapor contribution from a source point to a target point can be assessed if one performs a further simple (forward) operation on the identified trajectories with a consideration of water vapor evolution (evaporation and precipitation) along the trajectories. Sodemann et al. (2008) and Martius et al. (2013) reported interesting results about moisture source attribution within this simple framework.

However, this attribution calculation is only valid from a source point to a target point. It fails when one wants to evaluate an area for either the source or the target (or both). As a remedy of this drawback, Sun and Wang (2014) introduced a method called the areal source-receptor attribution to evaluate the contribution of a specific water vapor source region to the precipitation in a target region. When the air parcel is between the source and target regions, a normal operation is applied to calculate water vapor changes in function of evaporation (precipitation) that increases (decreases) water vapor. The specificity of the areal source-receptor attribution method is in its special treatments when the air parcel is in the source and target regions. Details can be found in Step 5 of the algorithm which is decomposed into seven steps and presented in Sun and Wang (2014). 
In our study, we further improve the methodology with two new aspects. First, we take

221

222

into account the water vapor in the initial air parcels (when the back trajectories reach a level

below $50 \mathrm{~m}$ and cannot go further), while Sun and Wang (2014) put this initial water vapor content at zero. This enhances the overall contribution rate of water vapor. Second, as also suggested in Huang et al. (2018), we consider a gaining of water vapor when parcels flow below the boundary layer top, where vertical mixing is dominant. Air parcels in this case are considered gaining water vapor as from the ground, while an increase of specific humidity above the boundary layer is mainly affected by a phase change of water vapor. In the latter case, we cannot directly assign the region as a source region.

A third improvement that we implemented in the initial algorithm of Sun and Wang (2014) is on the consideration of source region. The initial algorithm took into account only a well-determined source/target duality. In our work here, we extend the source region to an ensemble of unit surface areas of 1 by 1 latitude/longitude. This permits us to introduce the concept of Contribution Density Function (CDF), while Sun and Wang (2014) could calculate only the contribution proportion from source to target.

To summarize, we can now calculate, for each trajectory $\mathrm{j}$ departing from the grid $\mathrm{i}$, the quantity $R_{j}(i)$ representing the moisture gained from the unit surface area $i$ and then released in the target region. Let $\mathrm{R}_{\text {total }}$ be the precipitation falling down in the target. It should be the general sum of $\mathrm{R}_{\mathrm{j}}(\mathrm{i})$, i.e. the total moisture release from all trajectories (Sodemann et al., 2008; Sun and Wang, 2014, 2015; Chu et al., 2017). But it is actually a little larger than the general sum, due to the lack of trajectory calculations at very high layers. The contribution of water vapor from each unit area can be assessed with the Contribution Density Function (CDF), 
defined and calculated as:

$$
\mathrm{CDF}(\mathrm{i})=\frac{\sum_{\mathrm{j}=1}^{\mathrm{n}} R_{j}(i)}{R_{\text {total }}}(4)
$$

where $\mathrm{n}$ is the number of trajectories departing from the area i. CDF behaving as a 2-D probability density function can serve as a measure to evaluate the moisture contribution rate of a unit area $\mathrm{i}$ to the precipitations falling into the target area.

With the improvement that we implemented, the global integration of CDF is significantly increased, which indicates that we can more accurately identify water vapor sources for the precipitation. For example, the global sum of CDF for North China monsoon rainfall is about 0.8 with the original method (Sun and Wang, 2015), and about 0.9 with our modifications.

\section{Results}

Based on the methodology described in Section 2.3, we simulated the backward trajectory of parcels for EASM. From their initial positions shown in Figure 1, back-trajectories are calculated to cover all times during the four sub-periods of monsoon propagation in Figure 2 for 10 days.

\subsection{Pre-monsoon in South China}

For the pre-monsoon, rainfall mainly occurs in South China. Although it is before the onset of the South China Sea (SCS) summer monsoon, rainfall is still considered as part of EASM. We first analyze the moisture transport pathways (or channels) obtained as the mean trajectory which is the average of all back-trajectories departing from our pre-defined geographic sectors. Figure 3a shows the main water vapor transport pathways (or channels) during the pre-monsoon in South China. The trajectories proportions are also shown in 
relation to the channels. For the pre-monsoon in South China, the most important water vapor transport channel is from the West Pacific Ocean accounting for $33.3 \%$ of all trajectories. Air parcels come from the West Pacific Ocean, move northwestward across the Philippines, and finally enter the target area at the south boundaries. The average specific humidity of air parcels increases from 10 to $14 \mathrm{~g} / \mathrm{kg}$, which indicates that a significant portion of moisture is absorbed along the trajectories. The secondary moisture transport channel is from the Indian Ocean, which accounts for $24.6 \%$ of all trajectories. The average trajectories move across the Bay of Bengal, Indochina Peninsula and then move into South China. Contrary to the West Pacific channel, the average specific humidity of air parcels from the Indian Ocean decreases from 12 to $8 \mathrm{~g} / \mathrm{kg}$, which indicates a great deal of water vapor loss. $14.2 \%$ of the trajectories are from the Westerlies in the north, and their average specific humidity is small, increasing from 2 to $7 \mathrm{~g} / \mathrm{kg}$. Besides, the proportion of local trajectories is $6.5 \%$ and the South China Sea channel accounts for about $7.9 \%$ and the average specific humidity is $14 \mathrm{~g} / \mathrm{kg}$, the largest among all the channels. These results are consistent with our general expectation, and in agreement with Chen and Luo (2018) who also concluded that the main water vapor transport channel during pre-monsoon period in South China is from the Pacific Ocean. Nevertheless, the trajectory proportion obtained from our research is a bit higher for the Pacific Ocean and lower for the South China Sea.

The vertically-integrated water vapor transports within the Eulerian framework are shown in Figure 3b. The pre-monsoon in South China is mainly influenced by the West Pacific moisture transport channel. The circulation from southeast over the West Pacific carries abundant water vapor into the Indochina Peninsula and then affects South China. 
Compared to the water vapor channel from the West Pacific Ocean, the one from the Indian Ocean is relatively weak, but it also plays an important role for the pre-monsoon in South China. These results are consistent with the existing literature for this regard. For example, Chi et al. (2005) and Lin et al. (2014) showed already that before the onset of SCS summer monsoon, the subtropical high dominates the South China Sea and moisture reaching South China mainly comes from west winds over the Arabian Sea, east winds at the southwest flank of the Western Pacific Subtropical High and southwest winds over the Bay of Bengal.

However, the transport pathways cannot give precise moisture source/sink characteristics. Based on the evaporation-minus-precipitation diagnosis, Figure $3 \mathrm{c}$ shows the spatial distribution of average E-P from 1 to 10 days before air parcels reaching South China. It clearly reveals that the West Pacific is the most important moisture source region for the pre-monsoon in South China, and the maximum value is located in offshore areas of East China. East China and the South China Sea are also important moisture source regions. Moisture sink region for the precipitation in South China is mainly in the Indochina Peninsula, which indicates great moisture loss from the Indian Ocean.

The spatial distribution of moisture contribution leading to precipitations of pre-monsoon in South China (water vapor CDF) is shown in Figure 3d, obtained from the improved areal source-receptor attribution calculation. Large contribution density values are mainly located near the coasts of Southeast China, and the adjacent seas, with an average contribution density about $2 \times 10^{-3}$. In the West Pacific Ocean, the CDF of $1.0 \times 10^{-5}$ extends to $170^{\circ} \mathrm{E}$, and that of $1.0 \times 10^{-4}$ extends to $150^{\circ} \mathrm{E}$. However, $\mathrm{CDF}$ in the Indian Ocean monsoon region is relatively small, only the Bay of Bangel, the Indian subcontinent and the Indochina 
Peninsula show CDF values larger than $1.0 \times 10^{-5}$.

In summary, for the pre-monsoon in South China, the main moisture transport channel originates from the West Pacific which is consistent with a previous work of Chen and Luo (2018). The most important moisture source is also from the West Pacific providing abundant water vapor that is actually converted to precipitation in South China.

\subsection{Monsoon in South China}

After the onset of SCS summer monsoon, the entire regional atmospheric circulation jumps to a new state, EASM actually starts and enters into a stronger period. But main monsoonal precipitations remain in South China. Main moisture transport channels are shown in Figure 4. EASM is remarkably different from what it is in the precedent period. We can see, in Figure 4a, that the Indian Ocean moisture channel becomes the strongest one. The trajectories proportion increases from $24.6 \%$ (before the onset of SCS summer monsoon) to $53.9 \%$. More than half of the trajectories come from the Indian Ocean. The average specific humidity increases from 10 to $14 \mathrm{~g} / \mathrm{kg}$, which also indicates that water vapor for this period is mainly from the Indian Ocean. At the same time, the West Pacific Ocean shows an obviously weaker contribution. Only $22.0 \%$ of the trajectories come from the West Pacific Ocean and the corresponding pathway is a bit northward shifted, compared to the former period. Besides, trajectories from the westerlies and from local areas are also weakened, their trajectories proportions are only $6.5 \%$ and $4.9 \%$ respectively. These results are also consistent with previous works of Chen and Luo (2018) and Chu et al (2017). They divided the Indian Ocean channel into two channels and the sum of these two channels makes the total trajectories proportion at a level of about $50 \%$ which is very close to our result. The vertically-integrated 
water vapor transport, calculated within the Eulerian framework, confirms the conclusion (Figure 4b). During this period, the southwest monsoonal flow from the Indian Ocean strengthens rapidly and the whole South Asian monsoon system goes quickly into its mature stage, with a strong Somalian cross-equatorial flow, and monsoonal flows over the Arabian Sea, the Indian Peninsula, the Bay of Bengal, and the Indochina Peninsula, and finally over the South China Sea. This monsoonal flow inducing rainfalls in South China is now the main moisture channel. The West Pacific Ocean channel is rapidly weakened and its influence reduced. Such behaviors are in total agreement with what described in the current literature (e.g. Chi et al. 2005, and Li et al. 2014, among many others) which also show that after the onset of SCS summer monsoon, the subtropical high withdraws out of the South China Sea, and the powerful cross-equatorial flow crosses the Bay of Bengal and transports moisture towards South China. So, the Indian Ocean channel is the most important moisture transport pathway in this stage.

The spatial distribution of E-P is also calculated and shown in Figure 4c. We can see that after the onset of SCS summer monsoon, the maximum value of E-P is in north part of the South China Sea, moisture source from the Indian Ocean is stronger and that from the Pacific Ocean is weaker. As for moisture CDF (Figure 4d), the biggest value is in South China and north part of the South China Sea where the CDF value is larger than $2.0 \times 10^{-3}$. CDF in the South China Sea is about $5.0 \times 10^{-4}$. Compared to the rainy season before the onset of SCS summer monsoon, intensity of CDF is decreased in the West Pacific Ocean. Contours CDF of $1.0 \times 10^{-5}$ and $1.0 \times 10^{-4}$ extend to $165^{\circ} \mathrm{E}$ and $135^{\circ} \mathrm{E}$, respectively. This shows a clear westward shift. On the contrary, CDF in the Indian Ocean is obviously increased. CDF values for most 
352

353

354

355

356

357

358

part of the Indian Ocean are larger than $1.0 \times 10^{-5}$. CDF in the Bay of Bangel is larger than $1.0 \times 10^{-4}$

During the monsoon in South China, the Indian Ocean channel is the most important moisture transport channel, which includes more than half of the trajectories, and the contribution rate also increases a lot. Meanwhile the West Pacific Ocean impact is reduced. Besides, the biggest value of the moisture contribution is in South China and north part of the South China Sea.

\subsection{Monsoon (Meiyu) in the Yangtze-Huaihe River basin}

For the Meiyu period, the EASM propagates to the Yangtze-Huaihe River Basin, and leads to persistent rainfalls in this region. The moisture transport characters for this period have both similarities and differences with the former monsoon stage. During Meiyu, the IO channel is still the most important one and the portion of trajectories reaches to $42.1 \%$. The PO channel $(22.7 \%)$ and Westerly channel $(13.5 \%)$ are a bit strengthening. The spatial distribution of the vertically-integrated water vapor transport (Figure 5b) shows that the IO channel, the SCS channel and the PO channel converge in South China and move northward to converge in the Yangtze-Huaihe River Basin region, resulting in plum rain in this period. Xu et al. (2004, 2008), Zuo et al. (2009), Wei et al. (2012) and Jiang et al. (2013) also indicate that IO channel is the most important water vapor channel in Yangtze-Huaihe River basin.

The spatial distribution of E-P (Figure 5c) also shows some similarities with the former monsoon stage, main moisture source is found in the West Pacific Ocean, East China, the South China Sea and the Indian Ocean. It is interesting to note that the Indian Ocean channel is the main moisture pathway, but the Indian Ocean does not constitute the main moisture 
source. In fact, as shown in Figure 5c, the pathway from the Indian Ocean goes through the India Peninsula and the Indochina Peninsula, a significant part of moisture from the Indian Ocean is lost along the trajectories. By consequence, in the spatial distribution of CDF (Figure 5d), the Indian Ocean is not the most important moisture source with a contribution density to precipitation only about $1.0 \times 10^{-5}$ to $1.0 \times 10^{-4}$. The maximum of the contribution density, larger than $1.0 \times 10^{-3}$, is in the Yangtze-Huaihe River Basin itself and in South China. Compared to the monsoon in South China, the Meiyu period shows CDF decreasing in south and increasing in north. CDF in the Indian Ocean and South China Sea is in decrease, but the region of CDF exceeding $1.0 \times 10^{-5}$ extends to $50^{\circ} \mathrm{N}$.

For the Meiyu stage of EASM in the Yangtze-Huaihe River Basin, the most important moisture channel is still that from the Indian Ocean, which comprises $43.4 \%$ of the trajectories. But it has great moisture loss along the trajectories, so the moisture contribution for the precipitation is relatively small. The most important moisture contribution region is the Yangtze-Huaihe River Basin and South China.

\subsection{Terminal stage of monsoon in North China}

North China rainy season is the terminal stage of EASM. As the monsoon moves to North China, the rainy belt also shifts to North China and can stay for a few weeks. During the monsoon terminal stage in North China, the most important moisture transport paths change from IO to mid-latitude westerlies and to PO (figure 6a), the proportions for these two channels being $30.3 \%$ and $26.8 \%$ respectively. As shown in Figure 6b, the IO channel, the SCS channel and the PO channel move northward to North China, affecting the local rainfall. Mid-latitude westerlies also influence the rain belt. It should be noticed that, although the 
number of trajectories in mid-latitude westerlies is the biggest, specific humidity of this channel is small, so the vertically-integrated water vapor transport in this channel is relatively small. Our results confirm Jiang et al. (2017) who showed that Eurasia has the maximum parcels and the Pacific Ocean has the second largest number of parcels during the rainy season in North China.

Figure $6 \mathrm{c}$ is the spatial distribution of E-P for the terminal stage of EASM in North China. The main moisture source regions for the rainfall in North China are the eastern coastal areas of China, the northern part of the South China Sea and the Yangtze-Huaihe River Basin. Main moisture sink regions are North China, South China and the Indochina Peninsula. The spatial distribution of CDF to precipitation in North China indicates that the maximum value is still near the target area, and the average contribution density exceeds $5.0 \times 10^{-3}$. CDF in the south is further reduced, only the South China Sea and small areas east of Taiwan show CDF values higher than $1.0 \times 10^{-4}$. Meanwhile, $\mathrm{CDF}$ in the north is significantly increased. The region contour $1.0 \times 10^{-5}$ reaches to Balkhash Lake in the west and $60^{\circ} \mathrm{N}$ in the north. On the whole, the main moisture transport channels during the terminal stage of monsoon in North China are those from the mid-latitude westerlies and the West Pacific Ocean, with trajectories rates at $30.3 \%$ and $26.8 \%$ respectively. But there is low specific humidity from the westerlies channel, so the westerlies channel has little influence for the monsoon in North China. The most important moisture sources are from East China.

\subsection{Moisture transport evolution during the northward propagation of EASM}

From what shown above, it is clear that, accompanying the northward propagation of EASM, the main water vapor channel experiences profound changes. It is sourced in the West 
Pacific Ocean (PO) for the pre-monsoon in South China (SC). It changes then to the Indian Ocean (IO) when the monsoon sets up in SC and in the Yangtze-Huaihe River Basin. Finally the main water vapor channel is back to PO for the terminal stage of monsoon in North China. As shown in Fig. 7, the proportion of trajectories shows quite distinct behaviors for their seasonal evolution. The two channels from south and southwest (SCS channel and IO channel) increase firstly, and then decrease with northward shift of the rain-belt. In the contrary, the water vapor channels from the mid-latitude westerly, the West Pacific Ocean and the local moisture recycling show opposite characteristics, with an initial decrease followed by an increase.

Not only water vapor channels change profoundly following the seasonal course of the summer monsoon, the spatial distribution of water vapor contribution leading to rainfall also shows strong changes from one period to another. Figure 8 shows difference maps of CDF between two sequential stages. From the pre-monsoon to the onset of monsoon in South China, the moisture contribution from the Indian Ocean and the south part of the South China Sea has an obvious increase. Meanwhile, there are decreases of CDF in the north part of the South China Sea and in the West Pacific Ocean. This situation is largely expected since the onset of the monsoon in India and in South China implies much more water vapor coming from southwest. A large decreasing zone covering the Bay of Bengal, South China and the adjacent South China Sea reflects strong monsoon rainfalls in these areas. It is to be noted that there is a zone of increasing CDF in the northwest area of our target region, certainly related to the special topography in the lee side of the Tibetan Plateau.

When the monsoon rain belt reaches the Yangtze-Huaihe River Basin, we observe an 
440

441

442

opposite situation as shown in Figure 8b. There is a clear dipole with decreasing contribution from the south and increasing contribution from the north. The demarcation line is located around $25^{\circ}-30^{\circ} \mathrm{N}$. As we mentioned earlier, the northward shift of the research region reflects the seasonal migration of the summer monsoon which induces a systematic northward shift of the water vapor contribution. This phenomenon is also visible in Figure 8c displaying the changes of CDF when the monsoon shifts from the Yangtze-Huaihe River Basin to its terminal stage in North China. The water vapor from north is more important and that from south is less important. It should be noticed that the moisture contribution from the Pacific Ocean is larger, showing a more important role played by the West Pacific Ocean.

\subsection{Contribution from different source regions}

From what described previously, we can see that our Lagrangian trajectories can be quantitatively used to assess the intensity of moisture transport channels and determine the main pathway in each stage of the monsoonal northward propagation. The Evaporation-minus-Precipitation diagnosis considering the absorption and release of moisture along the trajectories can further determine the source characteristics of water vapor. Finally, the improved areal source-receptor attribution method allows us to quantify the moisture contribution of each source for the precipitation in the target region. With the northward propagation of EASM, significant changes take place in water vapor channels, including moisture sources and water vapor contributions to rainfall. In this section, we study furthermore the properties of CDF which is a new measure with powerful diagnostic abilities. We want to focus on its dynamic evolution in function of the monsoon northward propagation. 
To be consistent with the above-shown moisture transport channel, we use the same five

moisture source regions: (1) East China (EC), (2) West Pacific Ocean (PO), (3) South China

Sea (SCS), (4) Indian Ocean (IO) and (5) Eurasia (EA) (Figure 9, background map). We can now calculate the moisture contribution to precipitation for each of these source regions by just integrating the Contribution Density Function (CDF) for each region. It is also relevant to compare such regional contributions to the intensity of each moisture transport channel.

As shown in Figure 9, the moisture contribution from East China (EC) to regional precipitations is very high for all the four stages of the summer monsoon. This regional moisture contribution is well above the proportion of trajectories. In fact, all proportions of trajectories are under $10 \%$, but the moisture contributions are mostly over $30 \%$. This result clearly indicates that more than $30 \%$ of the moisture for precipitations in East China is originated from local evaporations. The local water recycling plays an important role for precipitation in each stage of the rainy season. Obviously, this kind of local evaporation is closely related to the hydrological conditions and vegetation behaviors of the underlying surface. In fact, it is closely related to early precipitations. Previous studies have also shown that soil moisture is an important factor for monthly and seasonal forecasting (Walker and Rowntree, 1977; Tuttle and Salvucci, 2016). Zuo and Zhang (2007) already pointed out that spring precipitation and soil moisture in East China exert an important effect on summer precipitation. It is remarkable that, after the onset of SCS summer monsoon, soil moisture accumulation in East China due to earlier precipitation enhances local evaporation and then precipitation. This is especially true for the terminal stage of monsoon in North China with a regional moisture contribution up to $55 \%$, reflecting that local water vapor recycling and 
484

485

precipitation in early rainy season play a very important role in the regional monsoon strength. In general, evaporation in East China plays an important role for the rainfall in EASM.

$\mathrm{PO}$ is also an important moisture source region contributing to precipitations in East China. The regional contributions from PO are all larger than $10 \%$. It is the highest $(25 \%)$ for the pre-monsoon in South China. The second largest contribution $(>20 \%)$ is found for the terminal stage of monsoon in North China.

The moisture contribution from SCS shows a big difference between the rainfall stage in South China and other two stages in the Yangtze River valley and in North China during the monsoon seasonal course. In South China, no matter before or after the onset of the SCS summer monsoon, the moisture contributions from SCS are both larger than $20 \%$, which constitutes an important moisture source. But when the monsoon goes to the Yangtze River basin and further to North China, this moisture contribution diminishes rapidly, until $5.1 \%$ in the terminal stage of monsoon in North China.

For the Indian Ocean, if we examine the proportion of trajectories, we can see that the IO water vapor transport channel is an important one for the whole monsoon course. This is in agreement with our general believing. In particular, for rainfall period in South China and the Meiyu in the Yangtze-Huaihe River valley, we can account about half of the trajectories. However, if we examine the moisture contribution to the actual precipitations, a different image appears. The contribution from IO is actually quite small. For the four sub-periods of the monsoon seasonal course, it is only $7.2 \%, 18.0 \%, 9.5 \%$ and $2.4 \%$ respectively. The main reason is that the pathway of the IO channel goes through the Indian Peninsula and the Indochina Peninsula which are important moisture sink regions to the rainfall in target region. 
Moisture is thus lost along the trajectories, which induces a low contribution from the Indian Ocean for precipitations in East China.

Eurasian land is another region for which the "true" moisture contribution rates are all lower than the proportions of accounted trajectories. As is shown in Figure 8, the trajectories rates are all larger than $10 \%$ except when the monsoon is in South China, but enhanced when the monsoon reached North China. For the latter case, the proportion of trajectories from mid-latitude westerlies reaches its peak value of $30.2 \%$. In terms of moisture contribution to precipitations, all contributions from EA are smaller than 3.5\%. The main reason is that the specific humidity of air parcels from EA is small (Figure 3a). Therefore, the impact on precipitation of EASM is also small.

In summary, with the northward migration of EASM during its seasonal course, the moisture transport channels and moisture source regions show continuous and significant changes. The main water vapor channel is firstly from PO for the pre-monsoon in South China. It is then from IO for the starting monsoon in South China and Meiyu in the Yangtze-Huaihe River Basin. Finally, it returns to PO in the terminal stage of monsoon in North China. And based on the evaporation-minus-precipitation diagnosis and the areal source-receptor attribution method, the main moisture source during pre-monsoon in South China is PO and EC and the contribution rates are $34.3 \%$ and $27.7 \%$, respectively. After the onset of South China Sea summer monsoon, EC and SCS are the most important moisture sources in this period, their contribution rates being both larger than 23\%. During Meiyu in the Yangtze-Huaihe River Basin and terminal stage of monsoon in North China, the moisture of this period mainly comes from EC, the contribution rate reaching to $40.9 \%$ and $55.3 \%$. And 
528

529

our results on water vapor channels are consistent with published literature, such as, Lin et al. (2014), Chen and Luo (2018), Zuo et al. (2009) and Jiang et al. (2017). But it is clear that main moisture actually contributing to EASM precipitations doesn't necessarily come from the strongest water vapor pathways. For example, trajectory proportions for IO are larger than $25 \%$ especially in the stage of monsoon in South China (53\%), but the moisture contributions are generally smaller than $10 \%$. This is mainly due to the fact that a large amount of water vapor is actually lost in the transport pathways through important moisture sink areas such as the Indian Peninsula and Indochina Peninsula. On the contrary, local water vapor recycling inside EC plays an important role for the regional precipitations, with contributions mostly over $30 \%$, although the trajectory proportions for EC are all under $10 \%$. The contribution rate can even exceed $55 \%$ for the terminal stage of monsoon in North China.

Our results seem qualitatively in agreement with Sun and Wang (2015) who emphasized the role of land evaporation in precipitations falling in the Yangtze-Huaihe river basin and in North China. Similar conclusions are also reported in Drumond et al. (2011a) for precipitations in different regions of China. One can also mention the work of Drumond et al. (2011b) investigating precipitations in the Mediterranean area. It was convincingly shown that local sources provide moisture for the Eastern Mediterranean and Western North Africa. However, if we quantitatively compare our results to those reported in Sun and Wang (2015), our results seem to give larger weights on evaporation along the trajectories. This is certainly due to the fact that we incorporated a rule of boundary layer water vapor source in our calculations.

\section{Conclusion and Discussion}


In this paper, we used the HYSPLIT platform to calculate Lagrangian trajectories of air

551

552

553

554

555

556

557

558

559

560

561

562

563

564

565

566

567

568

parcels that reach East China during the northward propagation of the East Asian Summer

Monsoon. Our study, with NCEP/NCAR reanalysis data as driving conditions, covers a long period from 1961 to 2010 to ensure the significance of results. In Supplementary materials S1 and S2, we explored the sensitivity of our results to two other datasets and to the use of a second Lagrangian trajectory model, FLEXPART. The difference is estimated below $5 \%$ among different datasets and below $10 \%$ between the two Lagrangian models. To fully explore the Lagrangian trajectories, we calculate the mean moisture trajectories to get the main moisture channel. Since water vapor is not a conservative tracer following the trajectories, we also elaborated the Evaporation-minus-Precipitation diagnosis and the areal source-receptor attribution of water vapor contribution. We can thus obtain a robust picture for the water vapor transport, including paths, moisture sources and moisture contribution from different regions to precipitations in EASM. Main findings are summarized as follows:

Four main water vapor channels and their contribution have significant changes while the rain-belt in East China propagates from south to north. These water vapor channels are from PO (West Pacific Ocean), IO (Indian Ocean), SCS (South China Sea) and the mid-latitude westerlies, respectively. And local transportation also plays an important role in each rainy season. In the pre-monsoon stage with rainfall in South China, the most important moisture transport channels are from PO and IO, the proportion of the trajectories being 33.3\% and $24.6 \%$ respectively, consistent with our general expectation. But main moisture sources are from East China and PO, with moisture contribution rates at $34.3 \%$ and $25.7 \%$ respectively, highlighting the role of local evaporation for precipitations. After the onset of the 
572 SCS summer monsoon, but when the monsoon rain-belt is still in South China, the IO channel 573 strengthens, with the trajectories proportion increasing to $53.9 \%$. This reflects the onset of the 574 Indian monsoon which enters into the South China Sea. Despite the Indian monsoon 575 strengthening, EC and SCS are, however, the most important moisture sources in this period, their contribution rates to precipitations being both larger than $23 \%$. For Meiyu in the Yangtze-Huaihe River basin, the IO channel is still the most important water vapor channel, which includes $42.1 \%$ of all the trajectories. But the contribution rate from East China to precipitations is the highest $(40.9 \%)$. East China becomes the most important moisture source region. When the monsoon is in its terminal stage in North China, the most important moisture channels are the mid-latitude westerlies channel and PO channel, their trajectories proportions being $30.3 \%$ and $26.8 \%$, and the local water vapor recycling in East China has the greatest contribution to rainfall in North China during this stage, its contribution rate exceeding $55 \%$.

It is worthy to emphasize that main moisture for the EASM precipitation doesn't necessarily come from the strongest water vapor pathways. For example, trajectory proportions for IO are all larger than $25 \%$ (exceeding $53 \%$ in the stage of monsoon in South China), but moisture contributions to rainfall are always smaller than $10 \%$. This counter-intuitive result is in fact quite logic, since a large amount of water vapor is lost in the transport pathways crossing important moisture sink areas such as the Indian Peninsula and Indochina Peninsula. On the contrary, local water vapor recycling inside East China plays an important role for the regional precipitations, with contributions mostly over $30 \%$, especially 
594

595

596

597

598

599

600

601

602

603

604

605

606

607

608

609

610

611

612

613

614

615

although the trajectory proportions for East China are all under $10 \%$.

Finally, we can see that our analysis based on Lagrangian trajectories provides very useful information on water vapor transport, its source-sink regions and its contributions to rainfall. Results are generally in agreement with Eulerian diagnosis of water vapor transport. The focus of this study was put on precipitations in East China during the northward migration course of the regional summer monsoon. We examined only climatological fields. It is necessary to extend the current study to investigating interannual and interdecadal variations of moisture transport.

Acknowledgments. Constructive comments from three anonymous reviewers were very helpful to improve an earlier version of this paper. We thank Dr. Sun Bo for his great help on technology guidance. We acknowledge the National Climate Center (NCC) of China (http://ncc.cma.gov.cn) for the observations and NOAA, the Air Resources Laboratory (ARL), from ARL's archives (http://ready.arl.noaa.gov/gbl_reanalysis.php) for NCEP/NCAR reanalysis data. This work is supported by the National Natural Science Foundation of China (41675081), and the National Key Research and Development Program of China (grant 2016YFA0600402). Zhengyu Liu is partly supported by the U.S. NSF and DOE. Laurent Li is partly supported by the French ANR project China-Trend-Stream.

\section{References}

Bertò, A., A. Buzzi, and D. Zardi, 2004: Back-tracking water vapour contributing to a precipitation event over Trentino: a case study. Meteorologische Zeitschrift, 13, 189-200, https://doi.org/10.1127/0941-2948/2004/0013-0189.

Brubaker, K. L., P. A. Dirmeyer, A. Sudradjat, and B. S. Levy, 2001: A 36-yr climatological description of the evaporative of warm-season precipitation in the Mississippi river basin. 
616

617

618

619

620

621

622

623

624

625

626

627

628

629

630

631

632

633

634

635

636

637
Hydrometeor,
2,
$537-557$,
$J$
2,

Hydrometeor., https://doi.org/10.1175/1525-7541(2001)002<0537:AYCDOT>2.0.CO;2.

Bottyán, E., G. Czuppon, K. Kármán, T. Weidinger, and L. Haszpra, 2014: Moisture source diagnostic for Hungary based on trajectory analysis and stable isotopic composition of precipitation. EGU General Assembly Conference Abstracts, Vol. 16.

Chang, C. P., 2004: East Asian Monsoon. World Scientific. 564pp.

Chen, B., X. Xu, and T. Zhao, 2013: Main moisture sources affecting lower Yangtze River Basin in boreal summers during 2004-2009. Int. J. Climatol., 33,1035-1046, https://doi.org/10.1002/joc.3495.

Chen, L., and Coauthors, 1991: East Asia Monsoon. China Meteorological Press, 362. (in Chinese)

Chen, Y., and Y. Luo, 2018: Analysis of Paths and Sources of Moisture for the South China Rainfall during the Pre-summer Rainy Season of 1979-2014. Journal of Meteorological Research, 32, 744-757, https://doi.org/10.1007/s13351-018-8069-7.

Chi, Y., J. He, and W. Wu, 2005: Features analysis of the different precipitation periods in the pre-flood season in South China. Journal of Nanjing Institute of Meteorology, 28, 163-171, https://doi.org/10.3969/j.issn.1674-7097.2005.02.003.

Chu, Q., Q. Wang, and G. Feng, 2017: Determination of the major moisture sources of cumulative effect of torrential rain events during the preflood season over South China using a Lagrangian particle model, J. Geophys. Res. Atmos., 122, 8369-8382, https://doi.org/10.1002/2016JD026426.

Connolley, W. M., J. C. King, 1993: Atmospheric water - vapour transport to Antarctica 
inferred from radiosonde data. Quarterly Journal of the Royal Meteorological Society, 119(510): 325-342, https://doi.org/10.1002/qj.49711951006.

Diem, J. E., and D. P. Brown, 2006: Tropospheric moisture and monsoonal rainfall over the southwestern United States. J. Geophys. Res. Atmos., 111(D16), https://doi.org/10.1029/2005JD006836.

Dirmeyer, P. A., K. L. Brubaker, and T. DelSole, 2009: Import and export of atmospheric water vapor between nations, J. Hydrol., 365, 11-22, https://doi.org/10.1016/j.jhydrol.2008.11.016.

Ding, Y., Z. Wang, and Y. Sun, 2008: Inter-decadal variation of the summer precipitation in East China and its association with decreasing Asian summer monsoon. Part I: Observed evidences. Int. J. Climatol., 28: 1139-1161, https://doi.org/10.1002/joc.1615.

Dominguez, F., P. Kumar, X. Liang, and M. Ting, 2006: Impact of atmospheric moisture storage on precipitation recycling. J. Climate, 19, 1513-1530, https://doi.org/10.1175/JCLI3691.1.

Dominguez, F., G. Miguez-Macho, and H. Hu, 2016: WRF with water vapor tracers: A study of moisture sources for the North American monsoon. Journal of Hydrometeorology, 17(7), 1915-1927. https://doi.org/10.1175/jhm-d-15-0221.1

Draxler, R. R., and G. Hess, 1998: An overview of the HYSPLIT_4 modelling system for trajectories, Aust. Meteorol. Mag., 47, 295-308.

Draxler, R. R., and G. D. Rolph, 2011: HYSPLIT (HYbrid Single-Particle Lagrangian Integrated Trajectory) Model; National Oceanic and Atmospheric Administration, Air Resources Laboratory READY Web site. https://ready.arl.noaa.gov/HYSPLIT.php. 
660

661

662

663

664

665

666

667

668

669

670

671

672

673

674

675

676

677

678

679

680

681

Drumond, A., R. Nieto, and L. Gimeno, 2011a: Sources of moisture for China and their variations during drier and wetter conditions in 2000-2004: a Lagrangian approach. Climate Research, 50: 215-225. https://doi.org/10.3354/cr01043.

Drumond, A., R. Nieto, E. Hernandez, and L. Gimeno, 2011b: A Lagrangian analysis of the variation in moisture sources related to drier and wetter conditions in regions around the Mediterranean Basin, Nat. Hazards Earth Syst. Sci., 11: 2307-2320, https://doi.org/10.5194/nhess-11-2307-2011,.

Eiras-Barca, J., F. Dominguez, H. Hu, D. Garaboa-Paz, and G. Miguez-Macho, 2017: Evaluation of the moisture sources in two extreme landfalling atmospheric river events using an Eulerian WRF tracers tool. Earth System Dynamics, 8(4), 1247, https://doi.org/10.5194/esd-8-1247-2017.

Gimeno, L., A. Drumond, R. Nieto, R. M. Trigo, and A. Stohl, 2010: On the origin of continental precipitation. Geophysical Research Letters, 37(13), https://doi.org/10.1029/2010GL043712.

Huang, R., Z. Zhang, G. Huang, and B. Ren, 1998: Characteristics of the water vapor transport in East Asian monsoon region and its difference from that in South Asian monsoon region in summer. Chinese J. Atmos. Sci, 22, 469-479, https://doi.org/10.3878/j.issn.1006-9895.1998.04.08.

Huang, W., X. He, Z. Yang, T. Qiu, J. S. Wright, B. Wang, and D. Lin, 2018: Moisture sources for wintertime extreme precipitation events over South China during 1979-2013. J. Geophys. Res. Atmos., 123, 6690-6712, https://doi.org/10.1029/2018JD028485.

Insua-Costa, D., and G. Miguez-Macho, 2018: A new moisture tagging capability in the 
682

683

684

685

686

687

688

689

690

691

692

693

694

695

696

697

698

699

700

701

702

703

Weather Research and Forecasting model: formulation, validation and application to the 2014 Great Lake-effect snowstorm. Earth System Dynamics, 9(1), 167-185, https://doi.org/10.5194/esd-9-167-2018.

Jiang, X., Y. Li, and X. Wang, 2009: Water vapor transport over China and its relationship with drought and flood in Yangtze River Basin. Journal of Geographical Sciences, 19, 153-163, https://doi.org/10.1007/s11442-009-0153-6.

Jiang, Z., J. He, J. Li, J. Yang, and J. Wang, 2006: Northerly Advancement Characteristics of the East Asian Summer Monsoon with Its Interdecadal Variations. Acta Geographica Sinica. 61, 675-686, https://doi.org/10.3321/j.issn:0375-5444.2006.07.001. (in Chinese)

Jiang, Z., W. Ren, Z. Liu, and H. Yang, 2013: Analysis of water vapor transport characteristics during the Meiyu over the Yangtze-Huaihe River valley using the Lagrangian method. Acta Meteorologica Sinica, 271, 295-304, https://doi.org/10.11676/qxxb2013.017. (in Chinese)

Jiang, Z., S. Jiang, Y. Shi, Z. Liu, W. Li, and L. Li, 2017: Impact of moisture source variation on decadal-scale changes of precipitation in North China from 1951 to 2010, J. Geophys. Res. Atmos., 122, 600-613, https://doi.org/10.1002/2016JD025795.

Lin, A., D. Gu, B. Zheng, C. Li, and J. Zhang, 2014: Anomalous transport of water vapor for sustained torrential rain and its variation. J. Trop. Meteor, 30, 1001-1010, https://doi.org/10.3969/j.issn.1004-4965.2014.06.001. (in Chinese)

Martius, O., and Coauthors, 2013: The role of upper-level dynamics and surface processes for Pakistan flood of July 2010. Quart. J. Roy. Meteor. Soc., 139, 1780-1797, https://doi.org/10.1002/qj.2082. 
704

705

706

707

708

709

710

711

712

713

714

715

716

717

718

719

720

721

722

723

724

725

Perry, L. B., C. E. Konrad, and T. W. Schmidlin, 2007: Antecedent upstream air trajectories associated with northwest flow snowfall in the southern Appalachians. Wea. Forecasting, 22, 334-352, https://doi.org/10.1175/WAF978.1.

Shen, R., and Coauthors, 1982: Low latitude circulation variation in the high and low level of convective layer and precipitation during the pre-rainy season in South China. Proceedings of the National Conference on tropical summer monsoon. Yunnan People's Publishing House, 10-21 (in Chinese)

Shi, Y., X. J. Gao, Y. G. Wang, F. Giorgi, 2009: Simulation and projection of monsoon rainfall and rain patterns over eastern China under global warming by RegCM3. Atmos. Oceanic Sci. Lett., 2, 1-6, https://doi.org/10.1080/16742834.2009.11446816.

Sodemann, H., C. Schwierz, and H. Wernli, 2008: Interannual variability of Greenland winter precipitation sources: Lagrangian moisturediagnostic and North Atlantic Oscillation influence, J. Geophys. Res., 113, D03107, https://doi.org/10.1029/2007JD008503.

Sodemann, H., and A. Stohl, 2009: Asymmetries in the moisture origin of Antarctic precipitation. Geophysical research letters, 36, 273-289, https://doi.org/10.1029/2009GL040242.

Sodemann, H., and E. Zubler, 2010: Seasonal and inter-annual variability of the moisture sources for Alpine precipitation during 1995-2002. Int. J. Climatol., 30, 947-961. https://doi.org/10.1002/joc.1932.

Stohl, A., and P. James, 2004: A Lagrangian analysis of the atmospheric branch of the global water cycle. Part I: Method description, validation, and demonstration for the August 2002 flooding in central Europe. J. Hydrometeorol., 5, 656-678, 
https://doi.org/10.1175/1525-7541(2004)005<0656:alaota $>2.0$. co;2.

Stohl, A., and P. James, 2005: A Lagrangian analysis of the atmospheric branch of the global water cycle. Part II: Moisture transports between earth's ocean basins and river catciunents. J. Hydrometeorol, 6, 961-984, https://doi.org/10.1175/JHM470.1.

Sun, B., and H. Wang, 2014: Moisture sources of semi-arid grassland in China using the Lagrangian Particle Model FLEXPART. J. Clim., 27, 2457-2474, https://doi.org/10.1175/JCLI-D-13-00517.1.

Sun, B., and H. Wang, 2015: Analysis of the major atmospheric moisture sources affecting three sub-regions of east China. Int. J. Climatol. 35, 2243-2257, https://doi.org/10.1002/joc.4145.

Sun, B., Y. L. Zhu, H. J. Wang, 2011: The recent interdecadal and interannual variation of water vapor transport over eastern China. Adv. Atmos. Sci., 28, 1039-1048, https://doi.org/10.1007/s00376-010-0093-1.

Tuttle, S., and G. Salvucci, 2016: Empirical evidence of contrasting soil moistureprecipitation feedbacks across the United States. Science, 352, 825-828, https://doi.org/10.1126/science.aaa7185.

Walker, J., and P. R. Rowntree, 1977: The effect of soil moisture on circulation and rainfall in a tropical model. Quarterly Journal of the Royal Meteorological Society, 103, 29-46, https://doi.org/10.1002/qj.49710343503.

Wang, B., H. Lin, Y. Zhang, and M. M. Lu, 2004: Definition of South China Sea monsoon onset and commencement of the East Asia summer monsoon. J. Clim., 17, 699-710, https://doi.org/10.1175/1520-0442(2004)017<0699\%3ADOSCSM>2.0.CO\%3B2 
748

749

750

751

752

753

754

755

756

757

758

759

760

761

762

763

764

765

766

767

768

769

Wang B. 2006: The Asian monsoon. Springer Science \& Business Media. 787pp.

Wei, J., P. A. Dirmeyer, M. G. Bosilovich, and R. Wu, 2012: Water vapor sources for Yangtze River Valley rainfall: Climatology, variability, and implications for rainfall forecasting, $J$. Geophys. Res., 117, D05126, https://doi.org/10.1029/2011JD016902.

Xie, K., and X. Ren. 2008: Climatological characteristics of atmospheric water vapor transport and its relation with rainfall over north China in summer. Scientia Meteorologica Sinica, 28, 5508-5514, https://doi.org/10.3724/SP.J.1047.2008.00014. (in Chinese)

Xu, X., L. Chen, X. Wang, Q. Miao, and S. Tao, 2004: Moisture transport source/ sink structure of the meiyu rain belt along the yangtze river valley. Chinese Science Bulletin, 49, 181-188, https://doi.org/10.1360/03wd0047.

Xu, X., X. Shi, Y. Wang, S. Peng, and X. Shi, 2008: Data analysis and numerical simulation of moisture source and transport associated with summer precipitation in the yangtze river valley over china. Meteorology and Atmospheric Physics, 100, 217-231, https://doi.org/10.1007/s00703-008-0305-8.

Zhou, T., and R. Yu, 2005: Atmospheric water vapor transport associated with typical anomalous summer rainfall patterns in China. J. Geophys. Res. 110, D08104, https://doi.org/10.1029/2004JD005413.

Zhu, Y., H. J. Wang, W. Zhou, J. G. Ma, 2011: Recent changes in the summer precipitation pattern in East China and the background circulation. Clim. Dyn., 36, 1463-1473, https://doi.org/10.1007/s00382-010-0852-9.

Zuo, J., H. Ren, W. Li, P. Zhang, and M. Yang, 2009: Intraseasonal Characteristics of Water 

https://doi.org/10.1002/cjg2.1417.

773 Zuo, Z., and R. Zhang, 2007: The spring soil moisture and the summer rainfall in eastern

774

775

776
China.

Chinese

Science

Bulletin

52 ,

3310-3312,

https://doi.org/10.1007/s11434-007-0442-3. 
777

778

779

780

781

782

783

784

785

786

787

788

789

790

791

792

793

794

795

796

797

798

\section{Figure Captions}

Figure 1. Location of the three rectangular target domains in East China, it is North China region $\left(35^{\circ}-43^{\circ} \mathrm{N}, 110^{\circ}-120^{\circ} \mathrm{E}\right)$, Yangtze-Huaihe River Basin region $\left(28^{\circ}-34^{\circ} \mathrm{N}, 110^{\circ}-123^{\circ} \mathrm{E}\right)$ and South China region $\left(20^{\circ}-26^{\circ} \mathrm{N}, 106^{\circ}-120^{\circ} \mathrm{E}\right)$ from north to south. Dots indicate locations of the observational stations in these three regions. Superimposed are three major rivers in East China: the Pearle river in the south, the Yangtze river in the middle and the Yellow river in the north.

Figure 2. Beginning and end dates of pre-monsoon in South China (dark blue, PSC), monsoon in South China (light blue, MSC), monsoon (or Meiyu) in the Yangtze-Huai River Basin (red, YHR) and monsoon in North China (green, NC) from 1961 to 2010.

Figure 3. Characteristics of moisture transport, moisture source and sink for the pre-monsoon in South China (SC). (a) Moisture transport channels based on average trajectories. Five transport channels are identified, from East China (EC), the West Pacific Ocean (PO), the South China Sea (SCS), the Indian Ocean (IO) and the Eurasian westerly (EA), respectively. Colors on the pathways indicate the average specific humidity of air parcels along the trajectories (units: $\mathrm{g} / \mathrm{kg}$ ). The thickness of the pathways represents the percentage of trajectories, also marked in numbers. Grey shadings are the number of particles weighted by specific humidity (units: $\mathrm{g} / \mathrm{kg}$ ) arriving in the target region (the rectangular zone) for day 10 . (b) The climatology of vertically integrated atmospheric water vapor transport (vectors, unit: $\mathrm{kg} \mathrm{m}^{-1} \mathrm{~s}^{-1}$ ) under the Eulerian view, only vector more than $50 \mathrm{~kg} \mathrm{~m}-1 \mathrm{~s}-1$ are shown, and 
799

800

801

802

803

804

805

806

807

808

809

810

811

812

813

814

815

816

817

818

819

820

shadings represent amount of the water vapor transport. (c) Mean E -P (unit: mm day ${ }^{-1}$ ) of air parcels in 1-10 days before reaching target region (the rectangular zone). (d) Water vapor

Contribution Density Function (CDF) showing the contribution of water vapor source regions (unit: $10^{-5}$, areas of 1 by 1 in latitude/longitude) to the precipitation in the target region of South China.

Figure 4. Same as in Figure 3 but for the starting phase of the monsoon in South China.

Figure 5. Same as in Figure 3, but for the phase of the monsoon (Meiyu) in the Yangtze-Huaihe River Basin

Figure 6. Same as in Figure 3, but for the terminal stage of the monsoon in North China

Figure 7. (a) Schematic showing the five main moisture channels from East China (EC) itself, the West Pacific Ocean (WPO), the South China Sea (SCS), the Indian Ocean (IO) and the Eurasian westerly (EA) that affect precipitation in East China. (b) Proportions of trajectories from different channels in function of the four major stages of the East Asian summer monsoon: pre-monsoon in South China (PSC), monsoon in South China (MSC) Meiyu in the Yangtze-Huaihe River basin (YHR) and terminal stage of monsoon in North China (NC).

Figure 8. Sequential changes of the water vapor Contribution Density Function (CDF) among the four stages of the summer monsoon course: stage 2 - stage 1 (left), stage 3 - stage 2 
821 (middle) and stage 4 - stage 3 (right) (unit: $10^{-5}$, areas of 1 by 1 in latitude/longitude).

822

823 Figure 9. Bar charts showing the proportion of trajectories (red bars in \%) and moisture 824 contributions (blue bars in \%) leading to precipitations in different stages of the summer 825 monsoon (PSC: pre-monsoon in South China; MSC: monsoon in South China; YHR: 826 monsoon or Meiyu in the Yangtze-Huaihe River basin; NC: terminal monsoon in North 827 China). Background map shows the division of geographic sectors (black boxes: East China, 828 South China Sea, Indian Ocean, West Pacific Ocean and Eurasia) used to account the 829 trajectories and moisture contributions.

830 


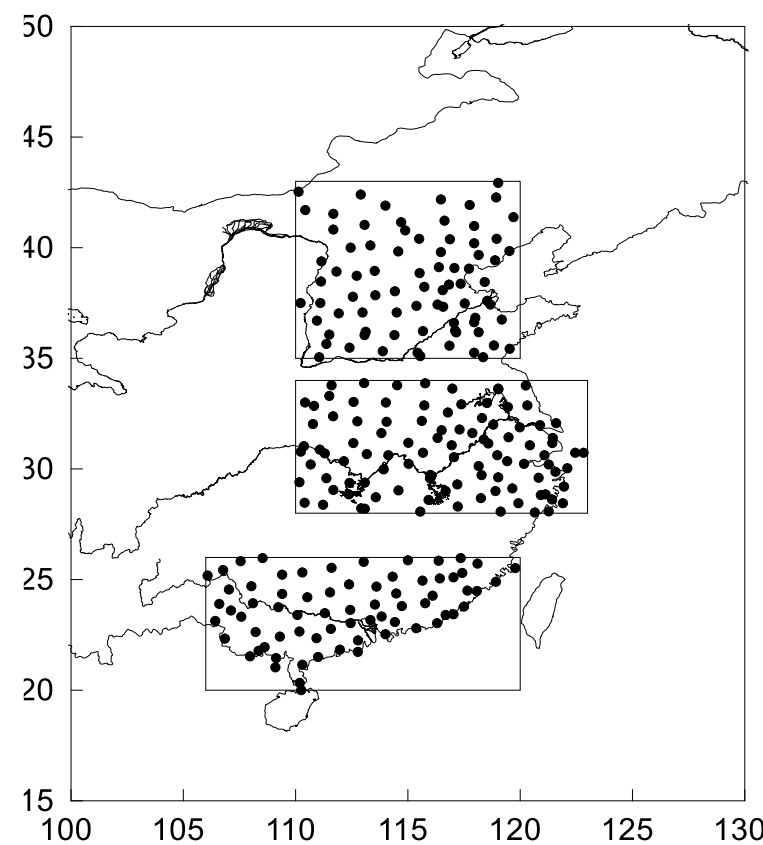

833 Figure 1. Location of the three rectangular target domains in East China, it is North China of the observational stations in these three regions. Superimposed are three major rivers in

837 East China: the Pearle river in the south, the Yangtze river in the middle and the Yellow river 838 in the north. 


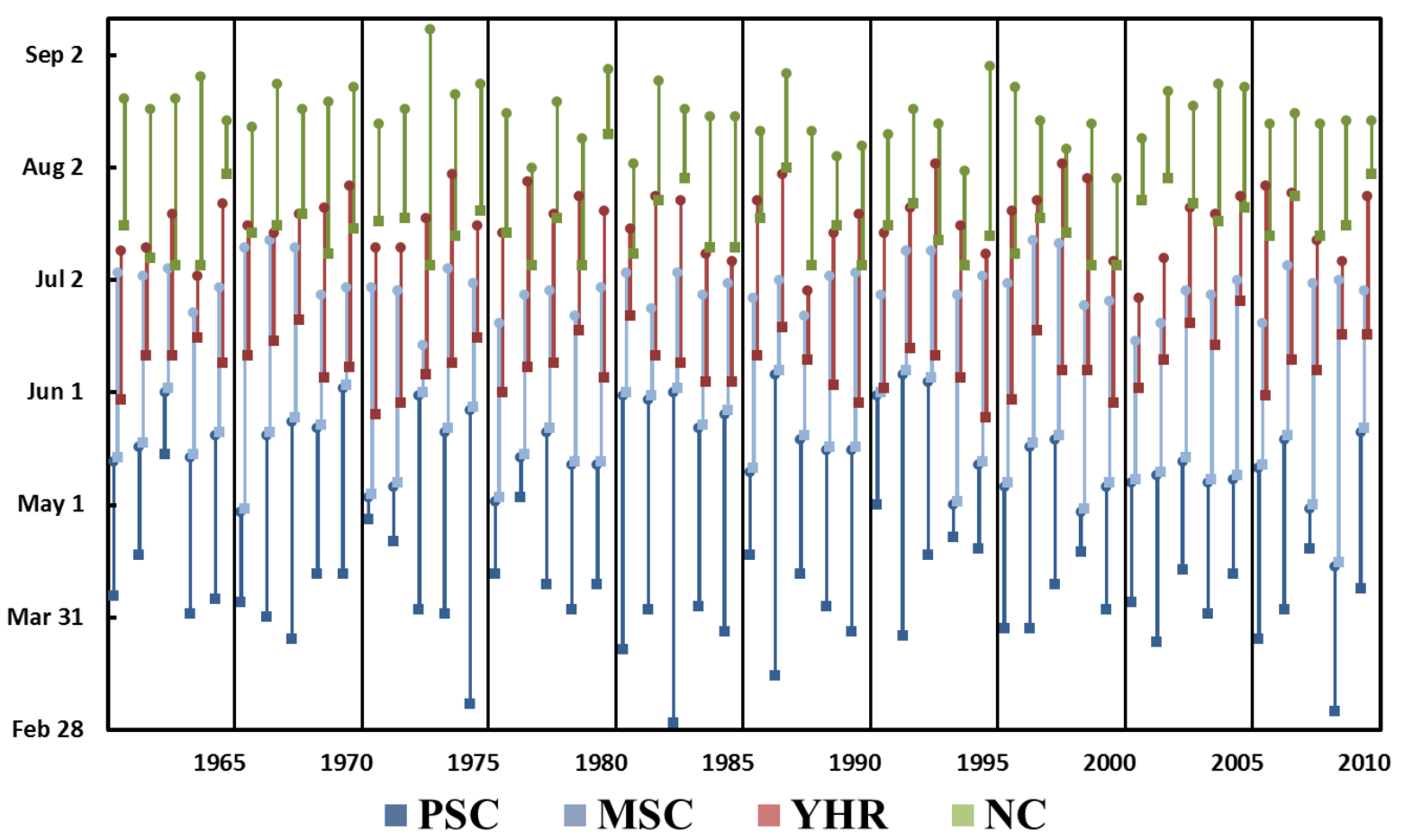

841 Figure 2. Beginning and end dates of pre-monsoon in South China (dark blue, PSC), monsoon

842 in South China (light blue, MSC), monsoon (or Meiyu) in the Yangtze-Huai River Basin (red,

843 YHR) and monsoon in North China (green, NC) from 1961 to 2010. 
(a)

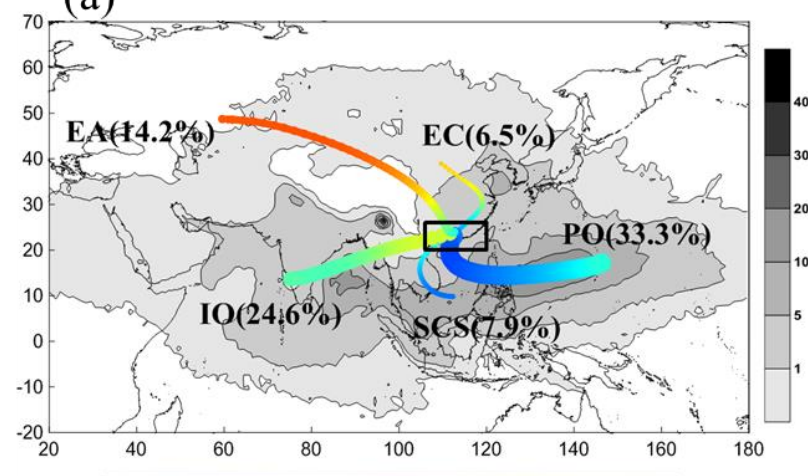

(c)

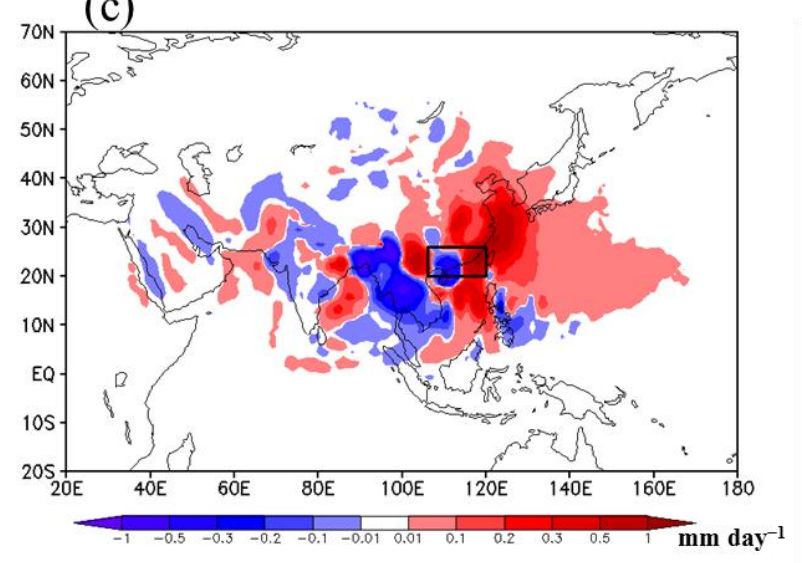

(b)

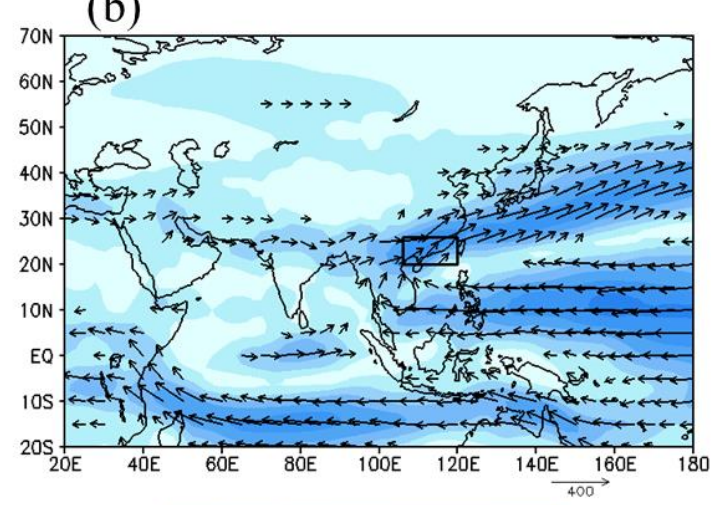

(d)

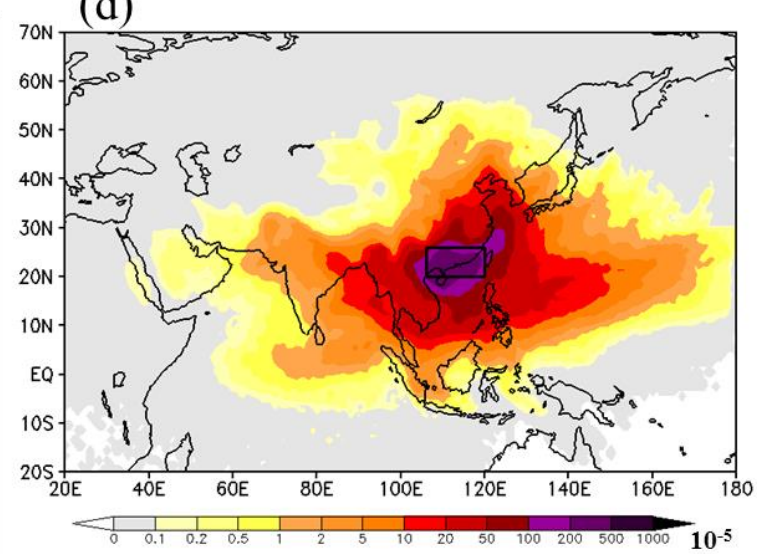

845

Figure 3. Characteristics of moisture transport, moisture source and sink for the pre-monsoon

in South China (SC). (a) Moisture transport channels based on average trajectories. Five transport channels are identified, from East China (EC), the West Pacific Ocean (PO), the

South China Sea (SCS), the Indian Ocean (IO) and the Eurasian westerly (EA), respectively.

Colors on the pathways indicate the average specific humidity of air parcels along the trajectories (units: $\mathrm{g} / \mathrm{kg}$ ). The thickness of the pathways represents the percentage of trajectories, also marked in numbers. Grey shadings are the number of particles weighted by specific humidity (units: $\mathrm{g} / \mathrm{kg}$ ) arriving in the target region (the rectangular zone) for day 10 .

(b) The climatology of vertically integrated atmospheric water vapor transport (vectors, unit: $\mathrm{kg} \mathrm{m}^{-1} \mathrm{~s}^{-1}$ ) under the Eulerian view, only vector more than $50 \mathrm{~kg} \mathrm{~m}^{-1} \mathrm{~s}^{-1}$ are shown, and shadings represent amount of the water vapor transport. (c) Mean E -P (unit: mm day ${ }^{-1}$ ) of air 
857 parcels in 1-10 days before reaching target region (the rectangular zone). (d) Water vapor 858 Contribution Density Function (CDF) showing the contribution of water vapor source regions 859 (unit: $10^{-5}$, areas of 1 by 1 in latitude/longitude) to the precipitation in the target region of 860 South China.

861 
(a)

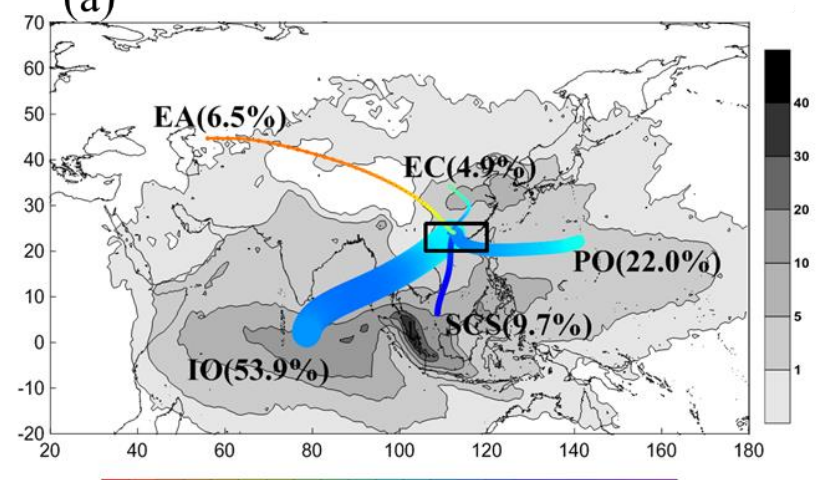

(c)

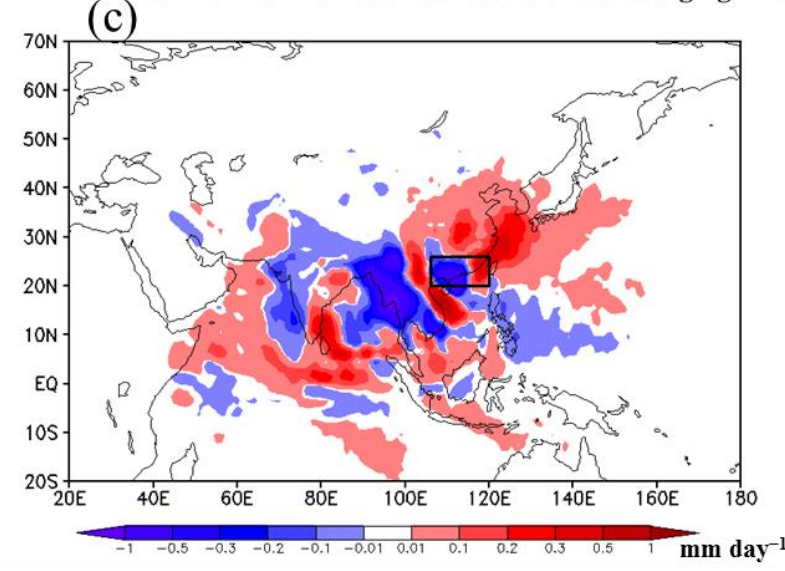

(b)

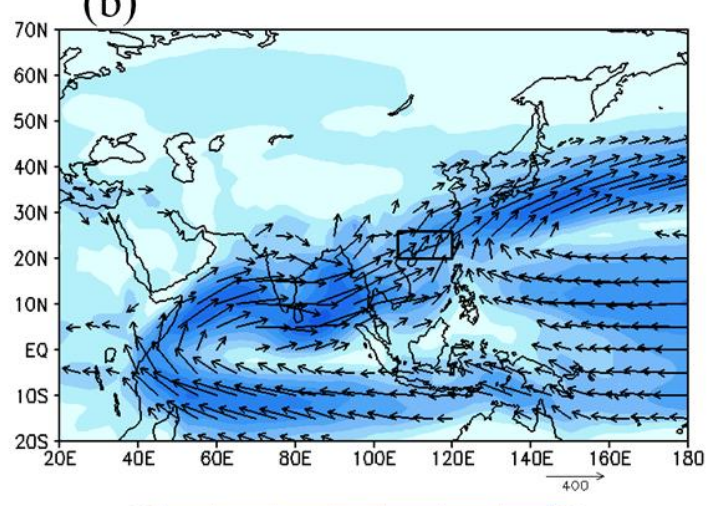

(d)

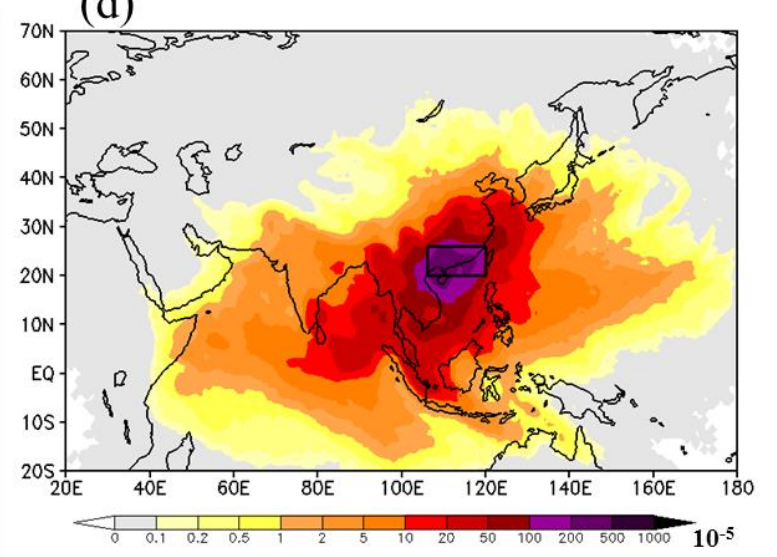

863 Figure 4. Same as in Figure 3 but for the starting phase of the monsoon in South China. 
(a)

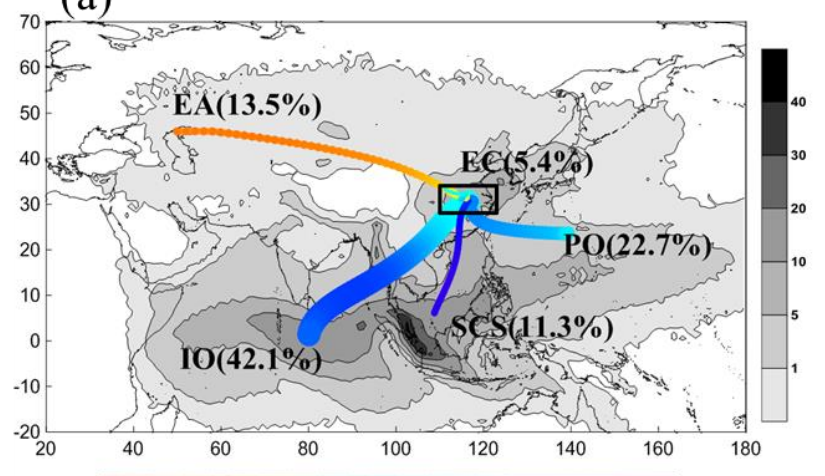

(c) (b)

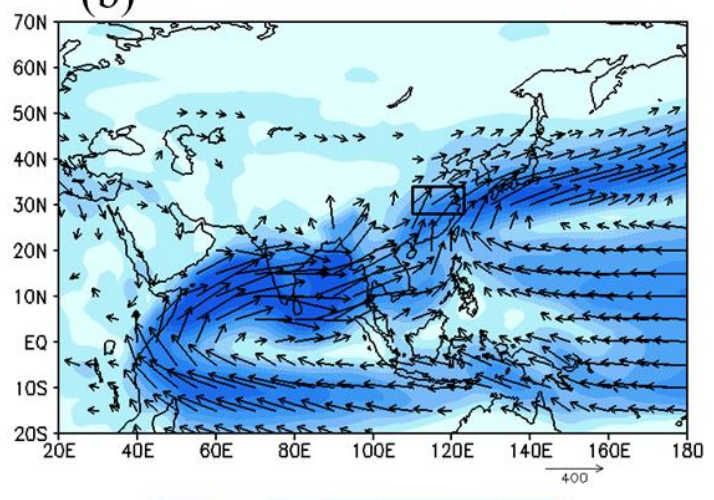

(d)
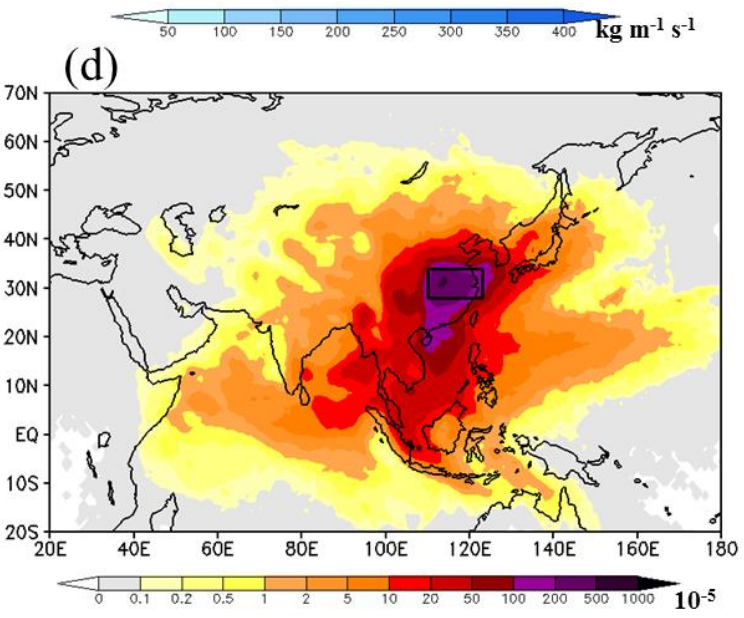

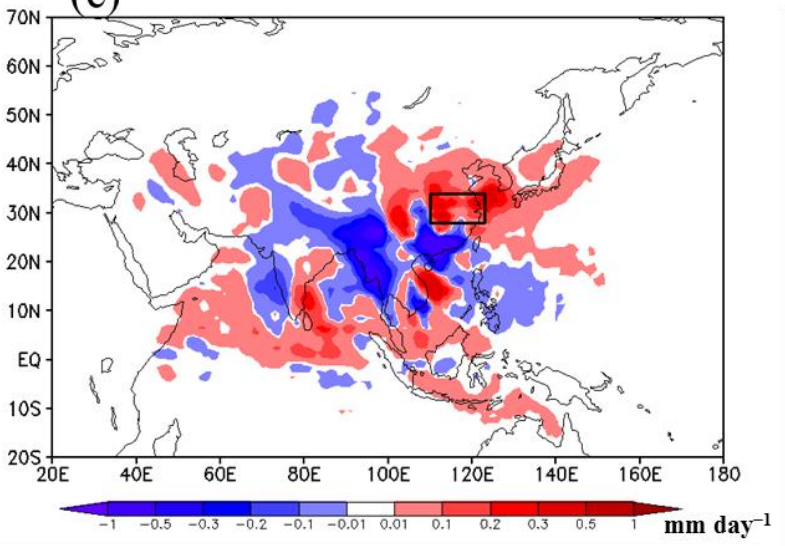

866 Figure 5. Same as in Figure 3, but for the phase of the monsoon (Meiyu) in the

867 Yangtze-Huaihe River Basin 
(a)

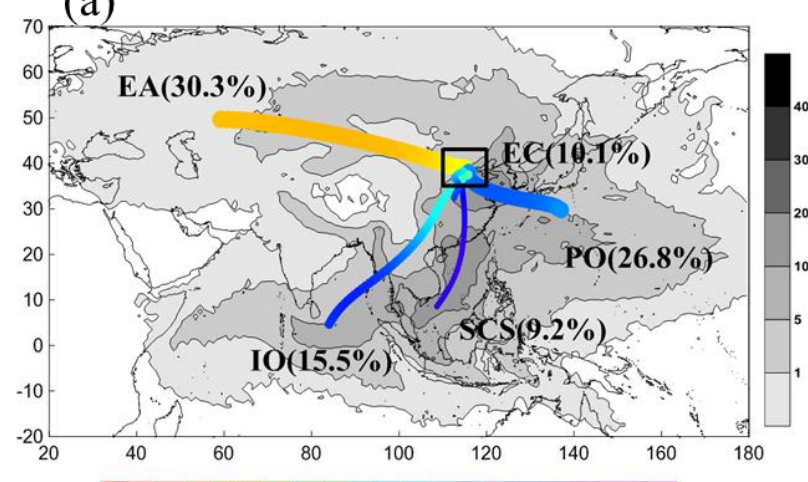

(c)

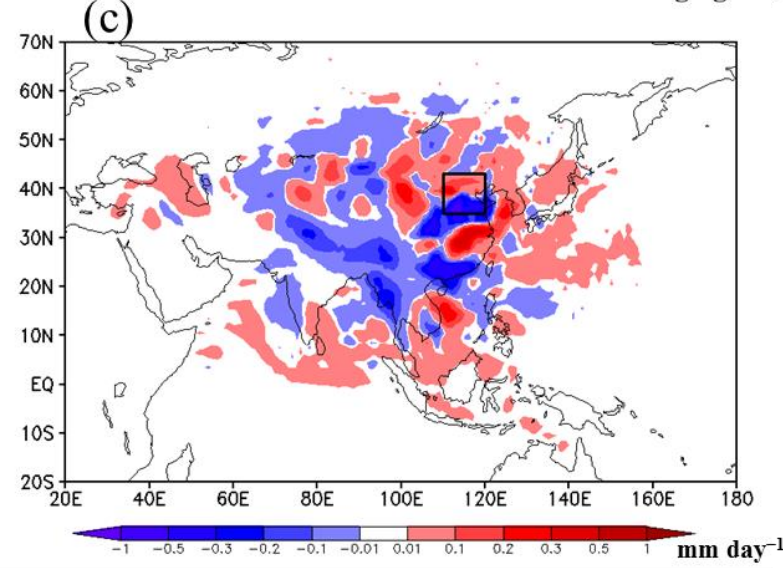

(b)

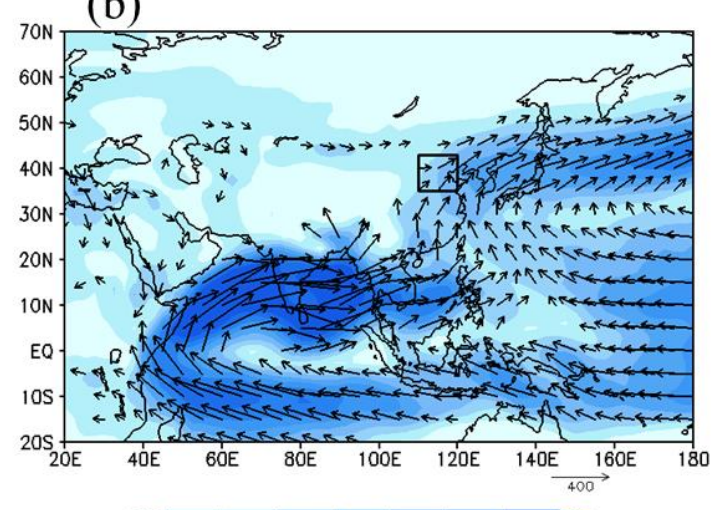

(d)

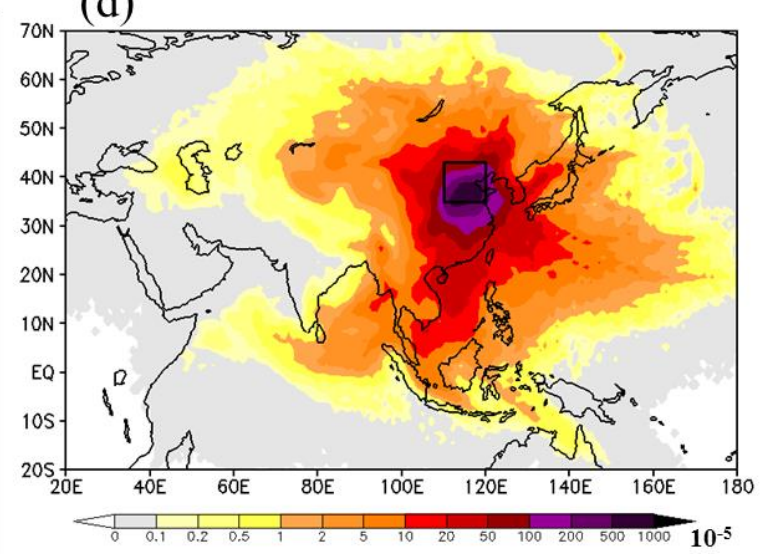

870 Figure 6. Same as in Figure 3, but for the terminal stage of the monsoon in North China 
70 (a)

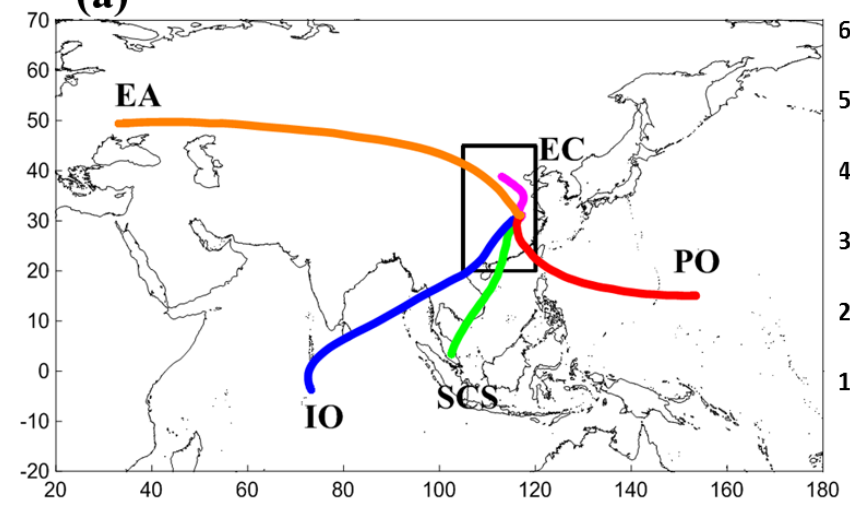

(b)

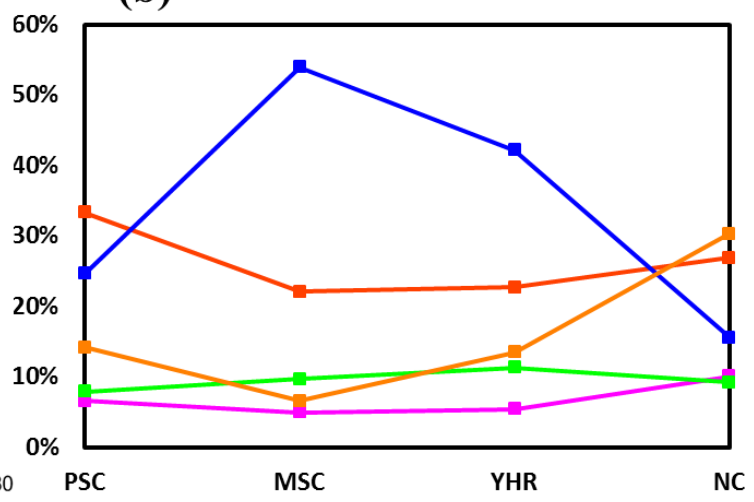

873 Figure 7. (a) Schematic showing the five main moisture channels from East China (EC) itself, 874 the West Pacific Ocean (WPO), the South China Sea (SCS), the Indian Ocean (IO) and the

875 Eurasian westerly (EA) that affect precipitation in East China. (b) Proportions of trajectories 876 from different channels in function of the four major stages of the East Asian summer 877 monsoon: pre-monsoon in South China (PSC), monsoon in South China (MSC) Meiyu in the 878 Yangtze-Huaihe River basin (YHR) and terminal stage of monsoon in North China (NC). 
(a)MSC-PSC

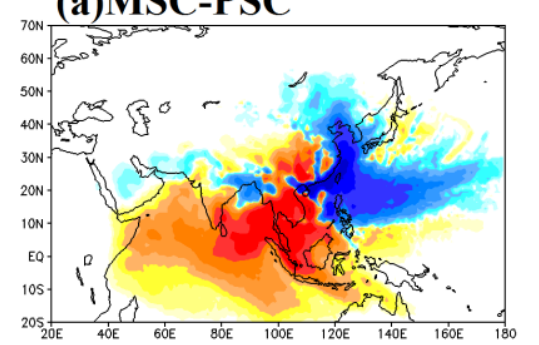

(b)YHR-MSC

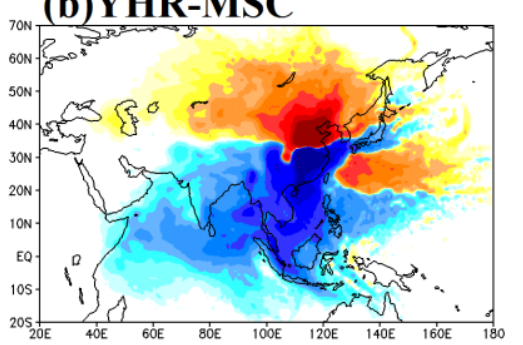

(c)NC-YHR

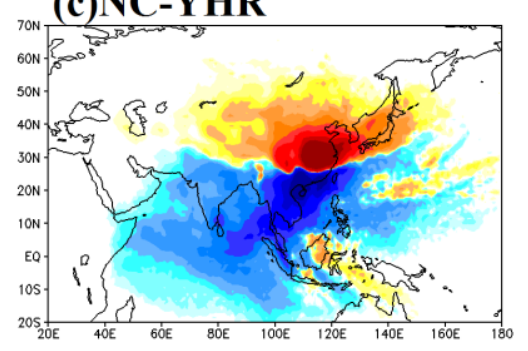

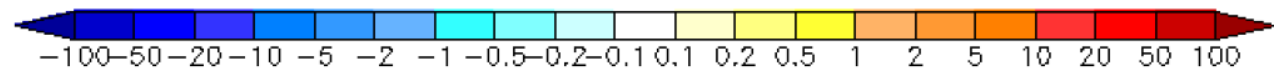

881

882 Figure 8. Sequential changes of the water vapor Contribution Density Function (CDF) among

883 the four stages of the summer monsoon course: stage 2 - stage 1 (left), stage 3 - stage 2

884 (middle) and stage 4 - stage 3 (right) (unit: $10^{-5}$, areas of 1 by 1 in latitude/longitude). 

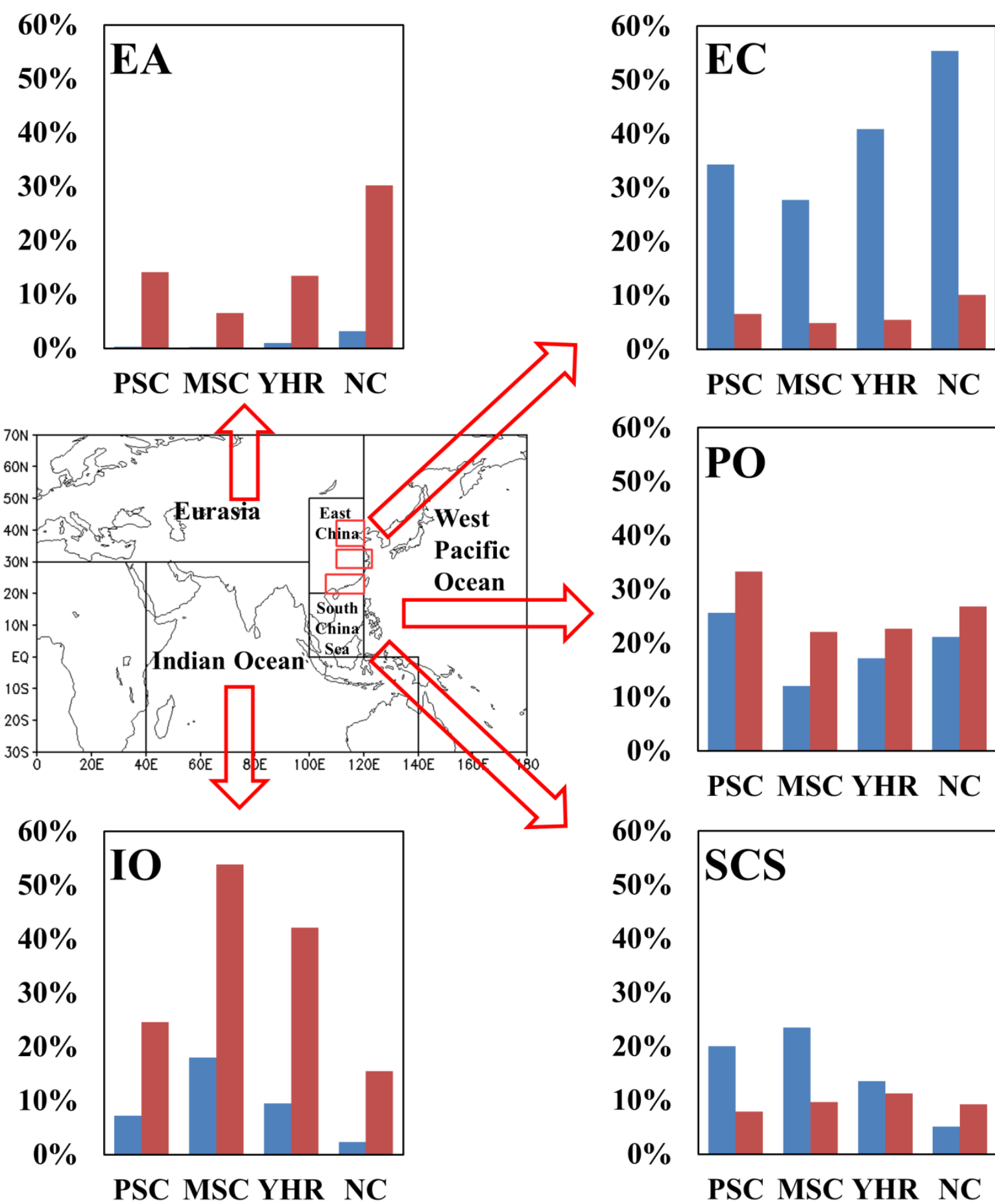

PSC MSC YHR NC

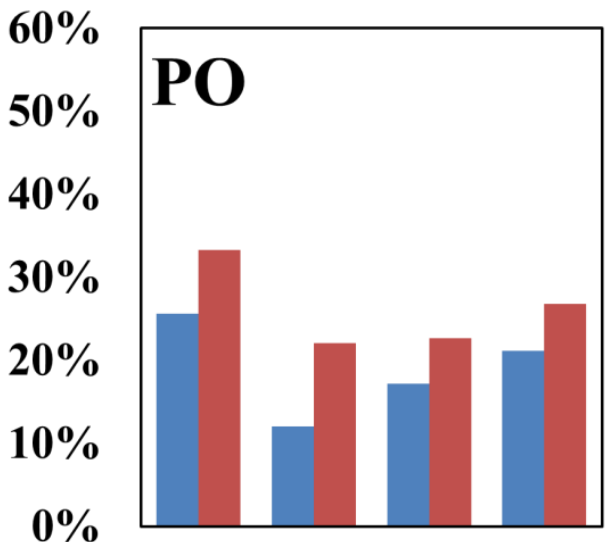

PSC MSC YHR NC

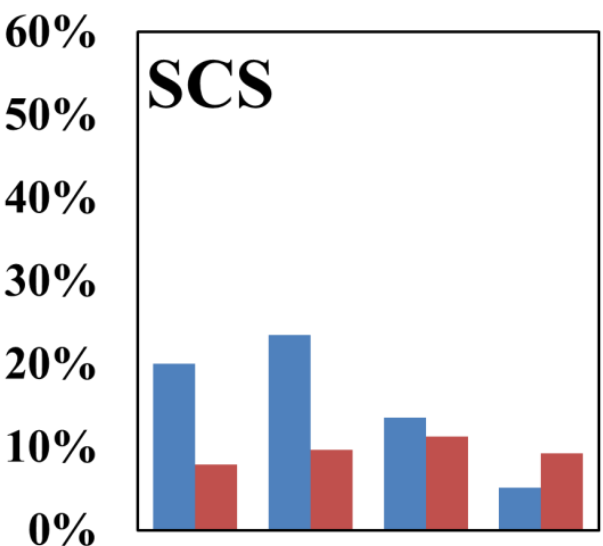

Figure 9. Bar charts showing the proportion of trajectories (red bars in \%) and moisture contributions (blue bars in \%) leading to precipitations in different stages of the summer 890 monsoon (PSC: pre-monsoon in South China; MSC: monsoon in South China; YHR: 891 monsoon or Meiyu in the Yangtze-Huaihe River basin; NC: terminal monsoon in North 892 China). Background map shows the division of geographic sectors (black boxes: East China, 
893 South China Sea, Indian Ocean, West Pacific Ocean and Eurasia) used to account the 894 trajectories and moisture contributions.

895 